\title{
The Role of Domed Shape Roofs in Energy Loss at Night in Hot and Dry Climate (Case Study: Isfahan Historical Mosques` Domes in Iran)
}

\author{
Mohammadjavad Mahdavinejad $^{1, *}$, Negar Badri ${ }^{2}$, Maryam Fakhari ${ }^{3}$, Mahya Haqshenas ${ }^{4}$ \\ ${ }^{1}$ Department of Architecture, Faculty of Art and Architecture, Tarbiat Modares University, Tehran, Iran \\ ${ }^{2}$ Department of Architecture, Faculty of Arts and Architecture, Tehran Paradise Fine Art University, Kish Campus, Kish, Iran \\ ${ }^{3}$ Department of Architecture, Faculty of Arts and Architecture, Tehran Paradise Fine Art University, Tehran, Iran \\ ${ }^{4}$ Department of Architecture, Faculty of Arts and Architecture, Tehran Paradise Fine Art University, Kish Campus, Kish, Iran \\ *Corresponding author: Mahdavinejad@modares.ac.ir
}

Received May 12, 2013; Revised June 22, 20103; Accepted July 20, 2013

\begin{abstract}
As a covering method of buildings `roof, domed roof have mostly been applied in Iran and other countries according to adobe material abundance comparing with timber ones. Furthermore, dome remains in first place in architectural designs due to their favorable thermal performance; so that it has been widely utilized in mosques, shrines, churches, bazaar and schools construction. On this account, the current research studies on the role of shape in roofs energy loss specifically in cold annual period to achieve the optimized form. The paper discusses a comparison to four types of roof (slab and three types of dome) in hot and dry climatic zone of Iran, Esfahan city. The research method is based upon modeling and simulation. It is to find the most efficient form of buildings which can be designed in contemporary architecture of developing countries. The result shows that although the flat shape roof appears in an appropriate thermal performance, there is a meaningful correlation between roofs total volumes and heating load at night, however the result is in need of further investigation.
\end{abstract}

Keywords: roof shape, domes, thermal performance, energy efficient methods, hot and dry climate

Cite This Article: Mohammadjavad Mahdavinejad, Negar Badri, Maryam Fakhari, and Mahya Haqshenas, "The Role of Domed Shape Roofs in Energy Loss at Night in Hot and Dry Climate (Case Study: Isfahan Historical Mosques` Domes in Iran).” American Journal of Civil Engineering and Architecture 1, no. 6 (2013): 117-121. doi: 10.12691/ajcea-1-6-1.

\section{Introduction}

Presently, energy demand, as a vital economic characteristic, plays an important role to increase energy price considering nonrenewable resources limitation and costs. Accordingly, parallel to efforts made to tackle the energy upgrading costs and absence, improving energy efficiency and conservation in buildings are considered as main solutions to address the problem.

Addition to applying thermal insulation in buildings, it is extremely significant to implement energy-efficient strategies and approaches to decrease energy transfer rate in construction sector. Directly influenced by climatic condition, building elements specifically, roofs play an important role in heat transfer rate in a structure and as buildings covering compose a large area of buildings envelope. The following paper develops the studies on roofs shape thermal behavior based on building heating load emphasizing on domed shaped covering (why domed model is widely used in Iranian architecture samples).

The role of domed shape roofs in energy loss at night in hot and dry climate is an attempt to find the most efficient form of buildings which might be suitable for contemporary architecture of developing countries especially in Iran. Case study of paper adopted as Isfahan historical mosques` domes why those are the most outstanding masterpieces of Iran.

Furthermore, paper uses a computerized simulation methodology as an alternative to field-based research. Modeled and analyzed three domed covering types, the final result will be discussed on.

\section{Domes and Domed Shaped Roofs in Traditional Architecture}

Domed roofs have traditionally been used throughout the world to cover large area and spans. In Iranian architecture, they have played another significant role of reducing the total heat gain from the roof and providing a passive cooling effect for the building they served [1]. Domes play very important role in building stability [2] therefore are very important in architectural design [3] especially when we want to interact traditional architecture and contemporary architecture of Iran. [4] Usage of indigenous architectural patterns and modeling traditional achievements [5] are suitable ways to fulfill a 
helpful strategy [6] for contemporary architecture [7] which roots in traditional architecture of hot and dry climate. In addition to Aesthetical characteristics, the presence of domed roof covered by glazed tiles and ventilation possibility through exterior skylight provide the monuments with more efficient thermal performance; so that, it was occasionally considered as a sole solution to optimally design in previous architecture and deal with extremities of the climate. Accordingly, long ago, there have been myths about ideal performance of dome shape roofs so that currently, many believe that it carries less energy loss in comparison to other architectural forms; whether correct, the claim has not experimentally proven.

\section{Methodology and Inference Mechanism}

Research Goals. Considering energy as an economic indicators, many industrial and developed countries apply energy friendly methods to compensate financial and economic issues related to. Furthermore, energy efficient design in building and its elements specifically roofs design plays an effective role to level down the rate of energy use in construction sector.

Moreover, as previously mentioned, widespread application of domed roof in traditional vernacular buildings appeals many research workers to the issue to discover the most influential parameters. Many researchers have analyzed and studied dome employment on different aspects specifically thermal behavior.

Accordingly, the paper intends to numerically achieve optimized form in domed shaped roofs while comparing it with a typical flat roof in traditional constructions in terms of geometry and evaluates thermal performance of aforementioned types.

Research Questions. The article is to find following questions answer:

1- What is the role of roof shape in energy loss at night?

2- Is there any relation between the arch of dome and energy loss characteristics?

Research Method. Research approach is simulation and computerized modeling [8] why it is not possible to have research on exactly same scale domed roofs and to accurately study on geometry effect on thermal behavior of roofs, it is essential to have same condition in buildings volume.

Applied techniques are numerical-comparative ones according to case study selection; so this paper uses computerized simulation methodology as an alternative to field-based research. Computerized simulation provides a virtual environment to survey the thermal behavior of building elements in details. The techniques of methodology, modelling and simulation by advanced numerical analysis software, as it is previously mentioned, are good alternatives for observational studies and he results won't have any time and numerical limitations and it is possible to erect any building.

In this research, energy plus software ver. 7 was used for simulation as an energy software which is an independent simulation engine to analyze buildings thermal behavior due to a wide range of energy outputs in comparison of other simulation engines. All models are individually simulated in this software. It discusses on daily heating load with an emphasis on energy demand at nights to compare all types thermal behavior while calculate the quantity of heating load by kw/h. The results one represented numerically and graphically. To have simulation methodology, as there is no environment for graphical modeling in energy plus firstly, the models are simulated in Autodesk Ecotect software, Version 2010, as a graphic medium and then the model geometry (saved as an .idf file) is transferred to energy plus software to be thermally calculated. The simulation weather date is based on Isfahan city, in hot and dry climatic zone, in Iran.

Therefore, the paper intends to find a relation between numerical simulation on thermal behavior and roofs geometry which depends on area and volume.

\section{Buildings Form and Energy Loss}

In the way of exploring sustainable solutions for energy efficiency construction, dow building solutions plays the leading and exploring role in energy consumption. Combined with global experience and local knowledge, there is a large scope of solutions to decline the rate of energy loss in construction industry. To Increase the efficiency of heating and cooling equipment, the insulation increase for the building envelop and imposing buildings standards all are considered as contemporary solutions toward minimizing energy loss [9]; however, there would be less tendency about pure architectural forms which leads to sustainability. Furthermore, in passive solutions toward energy saving, unlike the active ones, the architecture takes the most significant role according to creational design meeting energy conserving necessities. In this case, the first step inclines toward building volume and form. It means that if it is essential to use natural facilities to reduce energy loss, buildings type and envelope will be the first challenge to deal with [9]. So that, the integration of the method and applying appropriate building design techniques contributes to green echo-friendly buildings and societies [10]. The following essay initially studies on building forms and energy loss reduction while reporting the simulation and modelling results with an emphasis on optimum domed roof shape.

\section{Simulation Process}

\subsection{Mechanism of Case Studies Selection}

It is very important to clarify that in hot and dry regions of Iran, architects mostly used domed roofs to provide space coverage, particularly in dominant mosque constructions. Therefore, 10 survived samples of Esfahan mosques` dome are selected to study on. Case studies are provided for estimating heat loss through 4 types of roof including 3 types of domed roof and a flat one. To simplify the modeling, there are 10 categorized domes in 3 groups, based on their rise and the sector which is circumscribed under the dome. Therefore, the groups are: 


\subsection{Roof types}

All types are categorized in following groups:

Type 1, with an inscribed arc less than 180 degrees.
Type 2, with a 180 degrees inscribed arc.

Type 3, with an inscribed arc more than 180 degrees. Type 4, slab roof.

Table 1. Esfahan Domes `classification in 3 types, designed by authors

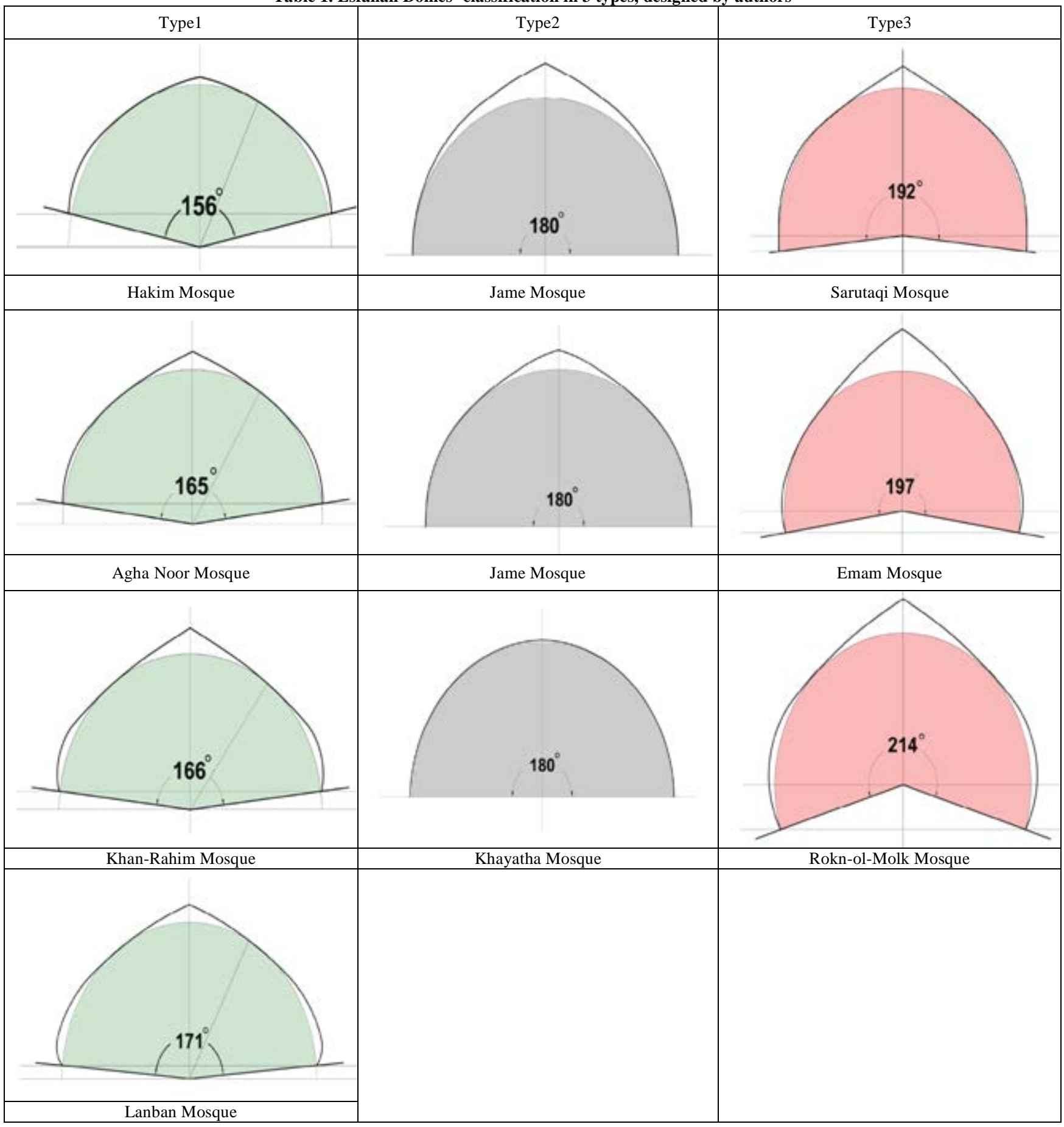

\subsection{Identifying the Polygons}

Three characteristic samples of each domed group are illustrated in table. These samples are: Hakim Mosque with an inscribed arc less than 180 degrees (Type1), Jame' Mosque with a 180 degrees inscribed arc (type 2) and Imam Mosque with an inscribed arc greater than 180 degrees (type 3). To numerically calculate and analyze, the circle at the base of the dome is replaced with a hex decagon. The dome is placed on a cylinder which is 10 meters in diameter and 4 meters in height. The rise height is divided into 1 meter segments; hence, the outer layer consists of similar trapezoids. With this meshing method, the surface area of each dome can be numerically calculated and finally the simulation results for the domes will be compared with a flat surface. Thus, thermal performance of samples is evaluated by the numerical simulation method using commercially available software. The following is a description of the parameters used for modeling.

As there is no graphical modeling device in Energy Plus; firstly, each type is separately simulated in Ecotect (Version 2010) and then imported to Energy Plus software (Version 7) to be calculated thermally. The ultimate result is illustrated on winter solstice (21th 
December) in a final graph to be easily compared. Figure 1 represents 3 types graphical modeling in Ecotect.
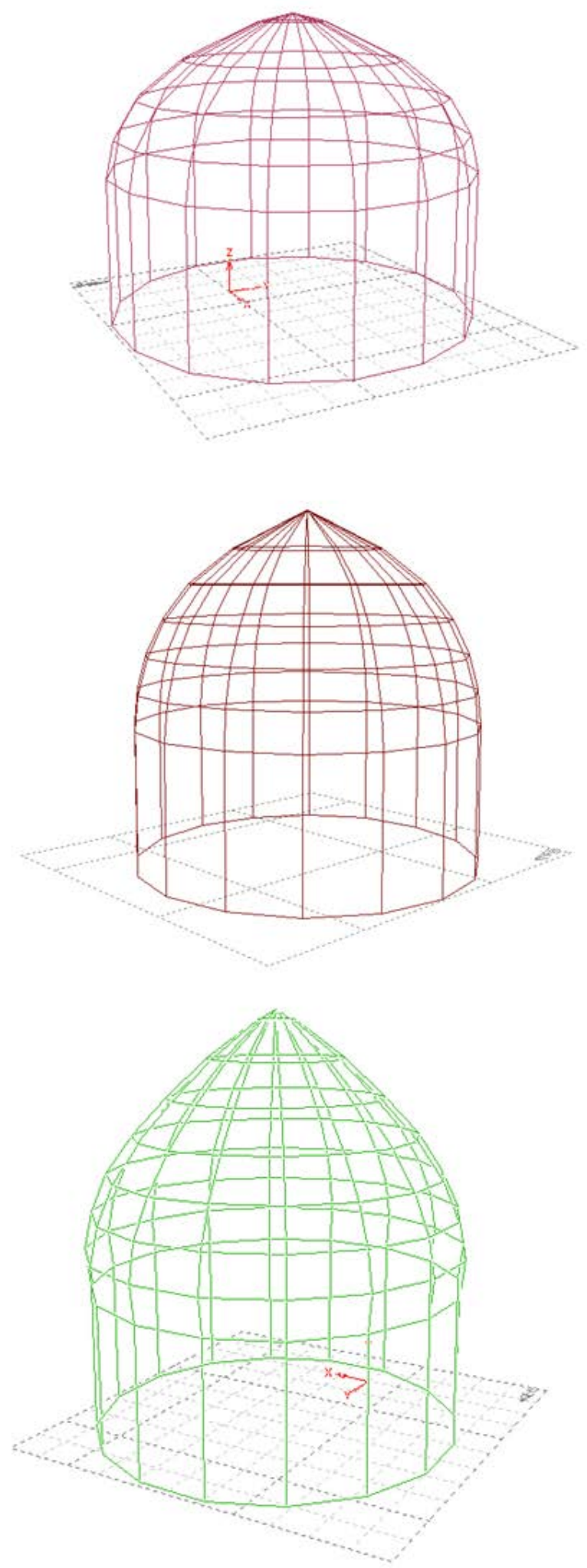

Figure 1. Domed roofs 3D and mesh modeling in Ecotect Software (Version 2010), Type 1: Hakim Mosque, Type 2: Jame Mosque, and Type 3: Imam Mosque; designed by authors

\section{Simulation Data:}

Location: Esfahan, Iran.

(Latitude: $32^{\circ} 38^{\prime} 0^{\prime \prime} \mathrm{N}$, Longitude: $51^{\circ} 39^{\prime} 0^{\prime \prime} \mathrm{E}$ )

Wall and roof Material: Brick masonry:

(Thickness of $30 \mathrm{~cm}$,
U-Value: $1.770 \mathrm{w} / \mathrm{m}^{2} \mathrm{k}$,

Time lag: 4hrs)

Day / time: 21 December (Winter Solstice).

Zone Comfort Temperature: $21^{\circ} \mathrm{C}$

Table 2. Total area and total volume quantities in 4 types`roof, designed by authors

\begin{tabular}{|c|c|c|}
\hline Roof Type & Total area $/ \mathrm{m}^{2}$ & Total volume $/ \mathrm{m}^{3}$ \\
\hline Type 1 & 330.78 & 495.858 \\
\hline Type 2 & 366.78 & 582.826 \\
\hline Type 3 & 390.348 & 635.044 \\
\hline Type 4 & 277.989 & 307.193 \\
\hline
\end{tabular}

\section{Discussion}

To achieve the goal, four roof models are calculated in software in terms of heating load emphasizing on the rate at night (which needs more energy consumption to achieve the human comfort zone in comparison to the rate in daylight).

Numerical modeling is indicative of the thermal performance of domed roof buildings while comparing them in terms of energy efficiency. Considering the same ordinary material (brick masonry), the thermal transmittance coefficient will be the same causing the area and volume (roof geometry) influence to be apparently studied on. However there is more dictators can be effective on. As represented in table 3, the least total rate of heating load refers to type 4 flat roof, which is about $46 \mathrm{kw} / \mathrm{h}$ in a daily calculation and $20.5 \mathrm{kw} / \mathrm{h}$ overnight time.

Comparing all other type, furthermore, Hakim mosque roof, as type 1 , has the most heating load rate both in day and night calculations which respectively is about 37.1 and $41.9 \mathrm{kw} / \mathrm{h}$. It seems type 1 behaves as the least efficient shape of the roofs.

Table 3. The comparison of heating load quantities in 4 type roofs,designed by authors

\begin{tabular}{|c|c|c|c|c|}
\hline $\begin{array}{c}\text { Heating } \\
\text { Load } \\
(\mathrm{Kw} / \mathrm{h})\end{array}$ & Type 1 & Type 2 & Type 3 & Type 4 \\
\hline $\begin{array}{c}\text { Heating } \\
\text { load } \\
\text { (Night) }\end{array}$ & 41.85 & 35.42 & 38.97 & 20.47 \\
\hline $\begin{array}{c}\text { Heating } \\
\text { load } \\
\text { (Day) }\end{array}$ & 37.12 & 31.5 & 35.093 & 25.59 \\
\hline $\begin{array}{c}\text { Total } \\
\text { Heating } \\
\text { load }\end{array}$ & 78.97 & 66.92 & 74.063 & 46.06 \\
\hline
\end{tabular}

Our calculation, moreover, shows that the correlation between heating load at night and total area which is ($54 \%)$ and in day is (-49\%). Also, the calculation displays a meaningful correlation between total volume and heating load in day and at night. Respectively, (-49\%) and $(-57 \%)$; Therefore, regarding to P-value and its 
characteristics (P-value < 0.02). All the results can be seen as meaningful ones, though they are not shown a linear correlation. Thus, the results are in need of further investigation and other interfering factors.

Table 4. Correlation test percentage between heating load and roofs 'area and volume, designed by authors

\begin{tabular}{|c|c|c|}
\hline Cor-Test & Night & Day \\
\hline Total area & -0.54 & -0.49 \\
\hline Total volume & -0.57 & -0.49 \\
\hline P-value & Night & Day \\
\hline Total area & 0.0000 & 0.0000 \\
\hline Total volume & 0.0000 & 0.0000 \\
\hline
\end{tabular}

\section{Summary}

Comparing all four models together in graph 1, the result shows that the less external area is, the rate of heating load and the same the rate of heat transfer flux will be less. So that, flat roof in type one with the least side area ,which is about $278 \mathrm{~m}^{2}$, behaves as the most efficient thermal performance due to a significant reduced volume over a daily period specifically with an emphasis on coldest night 21 December (Winter Solstice).

Moreover, based on the analysis of three other modeling and roof types, it seems that however dome type 1, (Hakim mosque), gets lower side area with an inscribed arch less than 180 degrees, energy load negligibly increases in calculation; The graph also shows that type two presents more appropriate thermal behavior however the first one performs as the most inefficient type why it has the most heating load over a day.

As difference in daily heating load in three domed types is a little in comparison to type 1, to have more accurate result, the paper suggests further investigation about the topics.

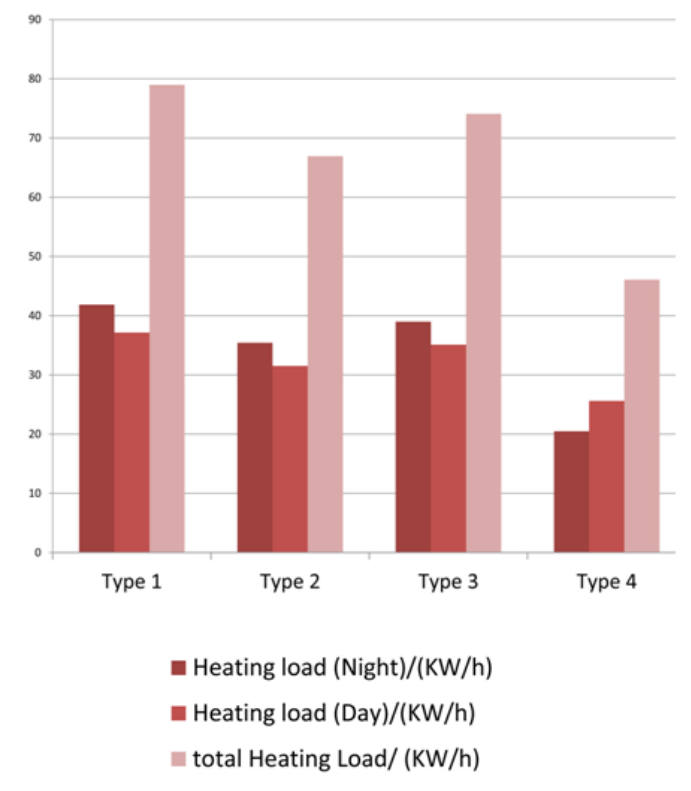

Graph 1. Final comparison of heating load in four type roofs, designed by authors

Nevertheless, it proposes following assumptions to achieve accurate assessment in extra research :
1. Since the roof height impressively influence buildings ventilation rate (which followed by building energy loss rate); It is recommended that the stack effect (vertical ventilation) is evaluated by using equation method in further advance research.

2. As it is can be seen that the mosque with a 180 degrees inscribed arc (type 2) has more energy efficiency comparing to other domed models, more types should be modeled and numerically simulated; why the final result will be compared in detail and more accurately.

3. According to various range of arcs type in domes, the angles of polygons should be separately calculated. Presumably, the inclination angle in domed roofs elements affect the rate of ultimate heating load in arched coverings. This also needs numerical computing and mathematical equations.

It is thought that the mentioned assumptions review would appear why the graph is in following order.

\section{Endnotes}

This article is adapted from a master thesis in Low energy architecture, Tehran University entitled "Establishment of Optimum Designing Pattern in Building Roof Shape to Achieve Energy Efficiency Based on Energy Loss”. The Author is Negar Badri and the dissertation is under supervision of Dr. Mohammadjavad Mahdavinejad and Dr. Rima Fayaz advice.

\section{References}

[1] F. Haghighat, M.N. Bahadori,. Thermal Performance Evaluation of Domed Roofs, Energy and Building 36, pp1254-1263. (2011).

[2] M. Mahdavinejad, M. Bemanian, G. Abolvardi, and S.M. Elhamian: Analyzing the state of seismic consideration of architectural non-structural components (ANSCs) in design process, International Journal of Disaster Resilience in the Built Environment, Vol. 3, Iss: 2, pp. 133-147, (2012).

[3] M. Mahdavinejad, A. Moradchelleh: Problems and Tendencies of the Development of the Architectural Sciences, Middle-East Journal of Scientific Research, 10 (6): 677-682, (2011).

[4] M. Mahdavinejad, A. Doroodgar, A. Moradchelleh: The Impacts of Revivalist Trends on the Contemporary Architecture of Iran (1977-2011), Middle-East Journal of Scientific Research, 11 (2): 176-183, (2012).

[5] M. Mahdavinejad, S. Ahmadzadeh Siyahrood, M. Ghasempourabadi, M. Poulad, M.: Development of Intelligent Pattern for Modeling a Parametric Program for Public Space, Applied Mechanics and Materials, Vols. 220-223, pp. 2930-2935, (2012).

[6] M. Mahdavinejad, A. Moradchelleh: The Impact of Family and Social Class on Efficiency of Arts Education and Learning, Middle-East Journal of Scientific Research, 11 (8): 1068-1077, (2012).

[7] M. Mahdavinejad, A. Moradchelleh: Family-Led Method in Art Education and Learning, Case: Tehran, Iran, Middle-East Journal of Scientific Research, 9 (4): 554-560, (2011).

[8] L. Groat, D. Wang, Architectural Research Methods, John Wily \& sons, Canada, pp.275-300, (2002).

[9] M. Soltandoost,.Heating, Cooling and Ventilation, Yazda press, Tehran, Iran, pp347-350. (2011).

[10] M. Mahdavinejad, M. Ghasempourabadi, H. Ghaedi,. The Role of Form Compositions in Energy Consumption of High-Rise Buildings, Advanced Material research 488-489, pp175-181. (2012). 